\title{
A Theoretical Model for Explaining Subscribers' Intention to Switch Back in Mobile Telecommunication Industry: Implications for Management
}

\author{
Simon Gyasi Nimako ${ }^{1}$ * \& Emmanuel Kofi Owusu ${ }^{2}$ \\ ${ }^{1}$ Department of Management Studies Education, University of Education, Kumasi Campus, Ghana \\ ${ }^{2}$ Department of Accounting Studies Education, University of Education, Kumasi Campus, Ghana \\ *Corresponding author: Department of Management Studies Education, University of Education, Kumasi Campus, \\ Ghana. Tel: 233-261-713-782. E-mail: sim.ekomerce@gmail.com
}

Received: June 17, 2014

doi:10.5430/mos.v2n1p107
Accepted: January 7, $2015 \quad$ Online Published: January 9, 2015

URL: http://dx.doi.org/10.5430/mos.v2n1p107

\begin{abstract}
The paper proposes a model for explaining factors that influence consumer intentions to switch back (unswitch) in the mobile telecommunication industry context. The proposed structural model was tested using data from a cross-section of 756 subscribers of six global mobile telecommunication companies. The findings indicate that consumer intention to switch back is influenced by switching motive, post-switching behaviour and attractiveness of firm's offer. Moreover, switching efficacy was found to moderate the effect of perceived attractiveness of firm's offer on intention to switch back. The theoretical and managerial implications are discussed.
\end{abstract}

Keywords: consumer switching; unswitching intention; switching motive; post-switching behaviour; switching efficacy; mobile telecommunication

\section{Introduction}

In the consumer behaviour literature, at least for the past decade, there has been much effort by scholars and practitioners to study consumer switching behaviour (CSB) in an attempt to inform theory and management strategy. In particular, many theoretical models have been developed to help understand the nature, antecedents and consequence of CSB (Bansal, \& Taylor, 1999; Bansal, Irving, \& Taylor, 2004; Bansal, Taylor, \& James, 2005; Keaveney, 1995; Nimako, 2012a). While much empirical work has been done on consumer switching, there is void in the consumer behaviour literature on consumer unswitching behaviour, the reverse of switching. Consumers switch and they are also able to switch back (unswitch). Like all other theoretical concepts that are developed from practice, there is evidence that firms' marketing strategies usually attempt to persuade consumers who have defected to return and renew relationship with previous service providers (Tokman, Davis, \& Lemon, 2007).

In competitive markets like the mobile telecommunication industry, many business firms' attempt to persuade consumers who have defected to return and renew relationship with them through various marketing strategies. In spite of the numerous research in consumer switching behaviour, very little is known empirically on theoretical models explaining intentions to unswitch among consumers.

In the mobile telecommunication context in many countries, there is intense competition as a result of the influx of take-overs and mergers of multi-national companies, especially in developing economies. This situation sets pressure on firms to put in measures to retain their customers. Aside this, the introduction of Mobile Number Portability (MNP) policy has helped reduce switching barriers and increased consumers' propensity and efficacy to switch among mobile networks (Buehler \& Haucap, 2004; Lin, Chlamtac \& Yu, 2003; Reinke, 1998). By the MNP consumers can now port their existing mobile phone numbers to other operator networks without changing their mobile numbers. This enables customers to switch among networks for their desired services. As a result of this switching platform, many firms do not only make attempts to win more customers, but also to persuade consumers who once switched to return. 
In Ghana's telecom industry, in 2008 when Vodafone Ghana took over the government-owned Ghana Telecom which had lost a significant market share, Vodafone Ghana put in place many promotional strategies to persuade defected customers to reconnect to Vodafone.

Similarly, in Nigeria, after the government transferred the management of NITEL and MTEL telecommunication companies in 2006 to TransCorp due to poor network connections and managerial problems facing them, the new management has been undertaking series of management strategies to attract previously switched customers to switch back (http://www.mobilecomms-technology.com/projects/nitel-gsm/). MTN Nigeria has also been working hard to provide quick and innovative marketing strategies to win back the confidence of their defected customers as a result of much customer complaints about poor customer service, bad network and high prices of the company's services (http://www.mobilecomms-technology.com/projects/nitel-gsm/).

In Kenya, Liquid Telecoms, the new owner of Kenya Data Networks announced its intentions to embark on new management and an upgrade and expansion of its network infrastructure to win fresh customers and win back the confidence of lost customers including Safaricom and MTN Business that defected due to poor quality of service (The East African, June 29, 2013).

In India, Bharti Airtel Limited (Airtel), the largest provider of mobile telephony and second largest provider of fixed telephony, has a strong, highly valued business analyst staff, that are responsible for developing win-back strategies to attract lost customers. Moreover, there were some significant decrease in subscriber base in March 2013 as some firms lost customers to others (Cellular news, 4th July 2013). This trend has set press on the telecom firms to, not only win new customers and retain existing ones, but also to attract lost customers.

China Mobile Communications Corp, the parent company of China's biggest telecom carrier, China Mobile Ltd, announced its intentions to offer commercial fourth-generation (4G) telecom services in 340 Chinese cities in 2014, in an attempt to win back lost customers which the company lost in the third-generation (3G) market, among other things (South Morning Midst Post, December 23, 2013).

Thus, persuading consumers to come back into relationship with previous service providers have been part of firms' marketing strategy for a long time (Tokman, Davis, \& Lemon, 2007). This is described as win back strategy. Yet, apart from a few studies that have examined qualitatively the intention of the switchers to come back to the former service providers (Roos, 1999b; Göransson \& Frenzel 2009; Tokman, Davis, \& Lemon, 2007), very little is known empirically regarding theoretical models for explaining consumer intentions to switch back to previous service providers in the telecom industry. This void in the marketing literature is the focus of this paper.

Understanding consumer unswitching behaviour may have important implications for marketing and consumer behaviour theory and practice. Research in these areas is needed to further our theoretical understanding about the nature and underlying factors that influence unswitching intentions and behaviour as well as its consequence on the consumer and the firm. This will also provide management and policy makers the empirical basis for developing evidence-based marketing strategies to win back defected customers. Given the void in marketing literature, this paper seeks to initiate theoretical enquiry into the factors that influence consumer unswitching behaviour, using the mobile telecommunication industry as the research context.

\section{Literature Review}

\subsection{Consumer Switching Behaviour (CSB)}

According to Nimako (2012a), "Consumer switching behaviour is the process by which a consumer abandons his/her relationship with a current service/product provider and replaces it with a competitor partially or entirely for a given time period." (p. 68). This comprehensive definition suggests several dimensions and typologies of the CSB phenomenon, notably, the fact that switching is a process and could be partial or total. In many research contexts, the idea of switching represents a complete or total switch from one service provider to another (Nimako, 2012a). The mobile telecom service industry represents one of the contexts where both partial and total switching situation are possible. Previous research in different service contexts indicates that consumer switching intention is influenced by determinants such as high prices, low satisfaction, poor service quality, low perceived value, unethical behaviour of service provider, poor corporate reputation, critical incidence, ineffective complaint handling, among others (Bansal, Taylor \& James. 2005; Bansal, Irving \& Taylor, 2004; Bansal, Taylor, \& James, 2005; Gerrard \& Cunningham, 2004; Chiu, Hsiehb, Roanc, Tsengc, Hsiehb, 2011; Omotayo and Abiodun, 2010).

Furthermore, several authors have also attempted to develop theoretical models for explaining the CSB phenomenon 
(Nimako, 2012b; Njite, Kim, \& Kim, 2008). A recent review of theoretical models in CSB literature (Nimako, 2012b) reveals that at least 10 theoretical models of CSB already exist. These models focused on understanding the determinants and process of consumer switching behaviour. While numerous studies have been done to enhance our understanding of the CSB concept, there is void of empirical research in the area of consumer unswitching behaviour and post-switching behaviour.

\subsection{The Nature of Unswitching Behaviour and Its Implications}

Consumer unswitching behaviour (CUSB) describes the situation where a consumer who once switched to a competitor decides to return back into relationship with the former service provider. The migration literature can help marketers understand the phenomenon of unswitching behaviour and consumer switching behaviour alike. Unswitching behaviour is a typology of migrants who return back to their former place of origin, either willingly or unwillingly (Bansal, Taylor and James, 2005). This is based on the assumption that the individuals are rational beings and would take necessary decisions and steps to move away on their own volition or under some external influence to their origin, when they judge it more beneficial to do so. In many competitive markets, firms attempt to use persuasive marketing strategies to win back the confidence of switchers or defected customers (Tokman, Davis, \& Lemon, 2007).

The consumer unswitching behaviour process may call for a great deal of effort and considerations on the part of consumers as the switching process may involve complex psychological, emotional and behavioural issues as well as the need to overcome some switching costs. Consumers may have underlying voluntary and involuntary motives for switching (Cheung, \& Lee, 2012; Chiu, Hsiehb, Roanc, Tsengc, Hsiehb, 2011; Keaveney (1995), think through a complex switching process to overcome several switching cost and barriers (Barroso \& Picón 2012; Bansal, Taylor and James 2005; Omotayo and Abiodun, 2010), and even after switching, may exhibit many post-switching behaviours towards the previous service provider (Keaveney, 1995).

When consumers switch service providers, they engage in a several types of post-switching behaviour. Keaveney (1995) found that $75 \%$ of switchers have told at least one person who is hproximate relative, co-workers or friend. She also found that most switchers engaged in active search for new providers and $85 \%$ of them found new service providers through active search, while other found new providers through marketing communication such as direct marketing, sales promotion and advertising media. These post-switching behaviour may impact on consumer intention to unswitch. Therefore, these underlying personal and social factors, firm and competitor factors, external and government consumer policy factors, among others, may have effect on consumers' intention to switch back to former service providers in different service contexts.

While consumer switching and unswitching appear to be similar, the two terms could be described as conceptually distinct. This is because whereas switching suggests a forward direction phenomenon in which consumers change from one service provider to another, unswitching suggests a backward direction phenomenon in which a consumer, who once terminated relationship with a service provider, now intends to renew the relationship with a former service provider. Renewing a once abandoned relationship with a service provider may have different implications for relationship marketing than may be apparent. Therefore, given that these two concepts are conceptually distinct, it might be useful to study the factors that could induce consumers to switch back in service contexts.

This study, therefore, examines determinants of consumer unswitching intention in the telecommunication industry, and focuses on the effect of factors such as telecom policy, perceived attraction and post-switching behaviour, switching motive on consumers' (switchers) intention to unswitch to their previous service providers. The following section discusses the conceptual framework and the hypotheses for this study.

\subsection{Research Model and Hypotheses}

The research model is presented in Figure 1 and depicts the hypothesized relationships of the effects of telecom policy (MNP), perceived attraction, post-switching behaviour and switching motives on consumer intention to unswitch. 


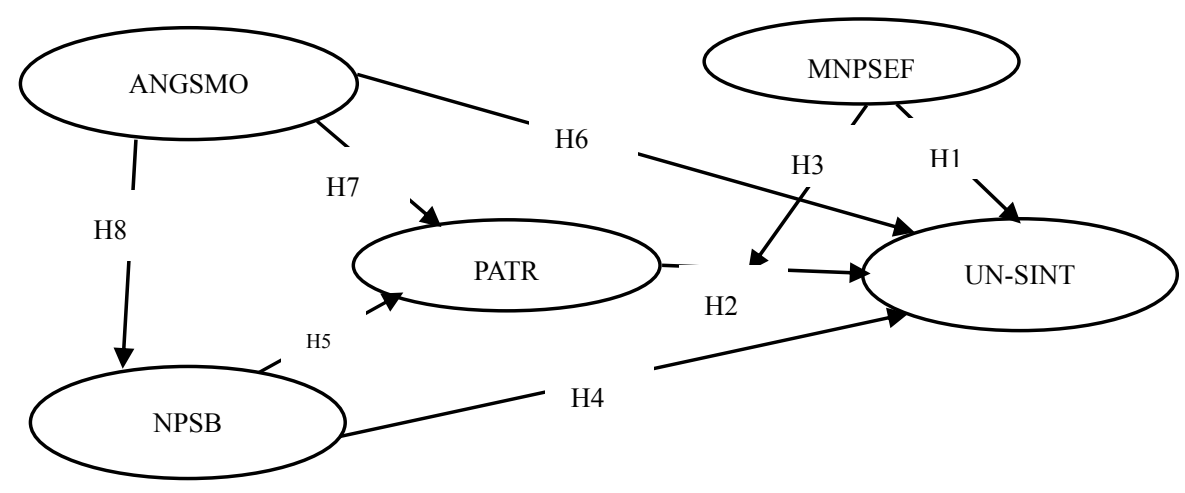

Figure 1. Research Model and Hypothesized Relationships

Notes: MNPSEF - Mobile number portability-induced self-efficacy, UNSINT - Unswitching Intention, PATR Perceived attraction, NPSB - Negative Post-switching Behaviour, ANGSMO - Anger-induced switching motive.

\subsubsection{Telecom Policy: MNP Policy}

MNP policy adoption in the mobile telecom industry is intended to facilitate consumer switching for better service quality (Buehler \& Haucap, 2004; Lin, Chlamtac, \& Yu, 2003). In effect, MNP provides the facility, resources and opportunity that causes consumers to belief in their ability to switch from one network to the other. In this way, MNP induces self-efficacy in consumer to switch, this is termed switching-efficacy. MNP-induced switching-efficacy is expected to facilitate not only switching intentions, but also unswitching intentions. In view of this, we hypothesis that:

H1: MNP-induced self-efficacy will have positively significant effect on intention to unswitch. Specifically, the higher the MNP-induced switching-efficacy, the higher will be the intention to unswitch.

\subsubsection{Perceived Attraction to Unswitch (PATR)}

Perceived attraction refers to the degree to which consumers are attracted by the offers of former service provider's (now the competitor) to unswitch. These attractive offers may be in the form of promising switchers higher service quality, network quality, value and satisfaction. In the switching behaviour literature, competitor attraction has been found to influence switching intentions (Bansal, Taylor, \& James 2005). As consumers compare values among firms depending on available information, they are motivated by perceived usefulness, value and service quality a firm promises them (Bansal, Taylor and James 2005; Keaveney, 1995). It follows that where a firm promises higher value and service quality to consumers than competitors do, they could attract switchers to switch back.

Thus, consumers may be willing to unswitch if they perceive that conditions (e.g., service quality and customer value) at the previous service provider have improved significantly and will be to their advantage. Additionally, in the telecom industry, the effect of perceived attractiveness of improved service quality on unswitching intention will be facilitated and moderated by MNP-induced switching-efficacy. This is because the effect of MNP is to reduce switching costs that act as barriers to switching in telecommunication industry (Barroso \& Picón 2012; Omotayo and Abiodun, 2010) Therefore, we postulate that:

H2: Perceived attractiveness of improved service quality will have significantly positive effect on intention to unswitch. Specifically, the higher the attraction, the higher will be the intention to unswitch.

H3: The effect of perceived attractiveness of improved service quality on intention to unswitch will be affected by MNP-induced self-efficacy. Specifically, the higher the switching efficacy, the higher will be the effect of perceived attraction on intention to unswitch.

\subsubsection{Negative Post-switching Behaviour (NPSB)}

Post-switching behaviour (PSB) is defined as behaviour consumers' exhibit after switching from one service provider to another. PSB could be manifested in consumer psychological (cognitive) attitude, affective (emotional) and behavioural responses. Keaveney (1995) found that, about $75 \%$ of consumers who switch are likely to tell at least one other person that are closely related to them about the switching incident and that such switchers are 
likely to engage in negative word-of-mouth communication. Such switchers may also try to make efforts to find new service providers through active external search, recommendations and referrals.

At the post-switching stage, consumers who engage in negative post-switching behaviour will be less likely to switch back unless they are attracted by stronger persuasions (DeCarlo, 2005). Thus, negative PSB (NPSB) could affect switchers' future switching behaviour, such as intention to switch back. NPSB is likely to affect, not only consumer intentions to unswitch, but also consumer perception of attractiveness of competitor's offer. Consumers who exhibit negative PSB will be less likely to respond positively to former provider's offers to unswitch. This could be due to the fact the negative post-switching behaviour tends to build strong, defensive and hostile psychological and emotional mechanisms in switchers, which make them resist persuasions to reconnect and unswitch (DeCarlo, 2005; Han, Lerner, \& Keltner, 2007; Loken, 2008). Therefore, we hypothesize that:

H4: Negative post-switching behaviour will have significantly negative affect on intention to unswitch. Specifically, the more unfavourable the consumer post-switching behaviour, the lower will be the intention to unswitch.

H5: Negative post-switching behaviour will have significantly positive affect on perceived attractiveness of competitor offer to unswitch. Specifically, the more unfavourable the consumer's post-switching behaviour, the lower will be the perceived attractiveness of competitor offer to unswitch.

\subsubsection{Switching Motive (SMO)}

Switching motive refers to the underlying reason for which consumers switch from one service provider to another (Roos, 1999b). In the consumer behaviour literature, two distinct behaviours, anger and happiness (satisfaction), underpin most reasons for choosing a course of action (Belanche, Casaló, \& Guinalíu, 2013). Therefore, a consumer may not switch from a service provider to a competitor even when service quality appears to be somewhat low, until he/she is provoked beyond some tolerance level of service quality and product performance as posited by proponents of zone of tolerance concept (Berry \& Parasuraman, 1991; Zeithaml, Berry, \& Parasuraman, 1993).

When consumer switching is motivated by anger, it is likely to put the service provider in a negative perception in the mind of a switcher. Therefore, anger-induced switching motives can negatively affect consumers' intention to unswitch. It may also determine several post-switching behaviour such as negative word-of-mouth communication, telling negative stories about service provider, telling others about the negative incidence that caused the switching and having negative emotions toward the previous service provider (Keaveney, 1995).

Moreover, such anger-induced switching motives could later affect the consumer's acceptance of any attractive offers by the previous service provider to unswitch. Therefore, it is hypothesized that:

H6: Anger-induced switching motive (ANGSMO) will have significantly negative influence on intention to unswitch. Specifically, the stronger the ANGSMO, the lower will be the consumer's intention to unswitch.

H7: Anger-induced switching motive will have significantly negative effect perceived attractiveness of competitor's offer. Specifically, the stronger the ANGSMO, the lower will be the consumer's perception of the attractiveness of competitor's offer.

H8: Anger-induced switching motive will have significantly positive effect on negative post-switching behaviour. Specifically, the stronger the ANGSMO, the stronger will be the consumer's negative switching behaviour towards the previous service provider.

\section{Methodology}

\subsection{Population and Sampling}

The population consisted of individual subscribers from all the six mobile telecommunication operators in Ghana, operating under the brand names: MTN Ghana, Vodafone Ghana, Airtel Ghana, Tigo, Expresso and Glo Ghana. A convenient sample size of 1000 respondents was chosen for the study. A survey was conducted from a cross-section of subscribers of mobile telecom service providers across the country in April 2013. Out of the 1000 questionnaire administered, a usable 756 were obtained representing $75.6 \%$ response rate.

\subsection{Research Instrument}

Since this study was part of a larger study on CSB, the part of the questionnaire that covers this paper is presented in Table 1. A self-administered, structured questionnaire was developed and pre-tested to a sample of twenty (20) customers. Adjustments were made based on the pre-test to refine the research instrument. 
The questionnaire was finally administered to mobile subscribers through personal contact by researchers for nearly two weeks. Since high predictive validity was a major concern, a five-point Likert scale was used as recommended in previous work (Danaher and Haddrell, 1996) to measure variables for the five research constructs. The Likert scale ranged from strongly disagree to strongly agree, coded 1 to 5 respectively, except for intentions to unswitch, which was measured on a five-point scale ranging from definitely yes, a bit yes, neutral, a bit no, to definitely no. In all, the measurement items for the five constructs had 12 items, some of which were developed based on previous studies and modified within the context of the mobile subscribers in Ghana's mobile telecommunication industry as shown in Table 1. The questionnaire also contained respondents' demographic data: gender, age, education, income, marital status, and type of mobile service network mainly used.

Table 1. Constructs and Measurement Items

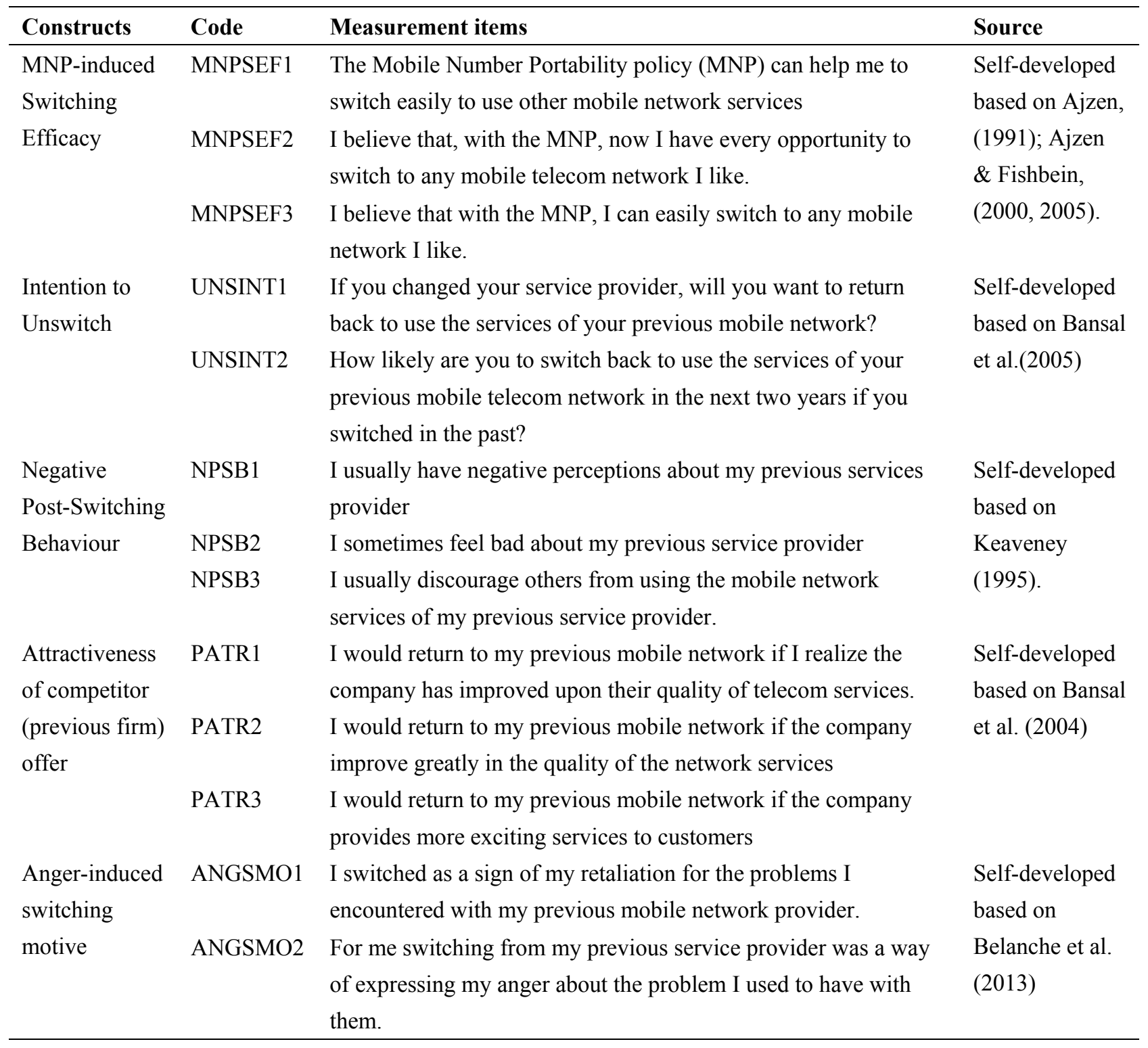

\section{Data Analysis}

\subsection{Respondents' Characteristics}

For the characteristics of the respondents, in terms of gender, $67.3 \%$ of the respondents were males and $32.7 \%$ were females. $38 \%$ of the respondents were below 25 years, about $30 \%$ of them were within the ages of 26-36 years, and about $2 \%$ were between above 41 years. This implies that majority of them were relatively young. All respondents 
were educated with about $77 \%$ of them having tertiary level of education, while about $21 \%$ and $2 \%$ had Senior High School (SHS) and other forms of education respectively.

In terms of monthly income, about $37 \%$ earned below US\$ $50,27 \%$ of respondents earned monthly income up to US\$ 250 , while about $32 \%$ earned between US\$ 250 and US\$ 500, and about $2 \%$ earned monthly income above US\$ 500.This indicates that most of them earned considerably low incomes. In terms of marital status, $71 \%$ of the respondents were married, about $27 \%$ were single (not married) and about $1 \%$ of them were in other marital category. About $1.1 \%$ were subscribers of Expresso telecom network, 58\% of Mobile Telecommunications Group (MTN) Ghana, $12.9 \%$ of Airtel Ghana, 3.6\% of Millicom Ghana Limited (Tigo), 22.5\% of Vodafone Ghana and less than $1.3 \%$ of Globacom Ghana.

\subsection{Method of Analysis for Proposed Model}

Data was analysed using SmartPLS 2.0 (Ringle, Wende, \& Will, 2005) to perform partial least squares structural equation modelling (PLS-SEM) to test the hypothesized relationships among the constructs in the proposed Model depicted (see Figure 1). PLS-SEM was deemed most appropriate because of the predictive focus of the study. Also, the study was meant to explore the measures of a relatively new concept of unswitching behaviour for further theory development (Chin, 2010). The SmartPLS 2.0 software was set to the following PLS Algorithm setting: Weighting scheme - path weighting scheme; Data metric - mean 0, var 1; Maximum Iterations - 300; Abort Criterion - 1.0E-5; and Initial Weights - 1.0. Bootstrapping setting: Sign changes - No sign changes; Cases - 756, and 500 bootstrap samples. Generally, the data analysis followed Anderson and Gerbing's (1988) two-step approach: estimation of the measurement model before the structural model.

\subsection{Measurement Model Reliability and Validity}

Construct reliability measures the extent of internal consistency of measures used, and it is assessed through Cronbach's alpha (Hair, Black, Babin, \& Anderson, 2010) with the acceptable level of 0.7 for basic research (Straub, Boudreau, \& Gefen, 2004) and also through composite reliability. From Table 3, three of the constructs have higher Cronbach alphas above 0.70 and three are close to it, indicating that these multiple measures are highly reliable for the measurement of each construct. Construct validity assesses the degree to which a measurement represents and logically connects the observed phenomenon to the construct through the fundamental theory (Fornell \& Larcker, 1981). It is assessed through convergent validity and discriminant validity (Hair et al., 2010).

Table 2. Cross Loadings for Convergent Reliability (model without interaction effect)

\begin{tabular}{lrrrrr}
\hline \multicolumn{1}{c}{ Construct/indicators } & \multicolumn{1}{c}{ MNPSEF } & UNSINT & \multicolumn{1}{c}{ PATR } & \multicolumn{1}{c}{ NPSB } & ANGSMO \\
\hline MNPSEF1 & $\mathbf{0 . 8 5 5}$ & 0.056 & 0.040 & -0.002 & 0.066 \\
MNPSEF2 & $\mathbf{0 . 8 5 3}$ & 0.056 & 0.102 & 0.050 & 0.070 \\
UNSINT1 & 0.044 & $\mathbf{0 . 9 0 0}$ & -0.123 & 0.129 & 0.053 \\
UNSINT2 & 0.074 & $\mathbf{0 . 8 7 5}$ & -0.129 & 0.075 & 0.034 \\
PATR1 & 0.083 & -0.130 & $\mathbf{0 . 8 4 3}$ & 0.102 & 0.308 \\
PATR2 & 0.081 & -0.140 & $\mathbf{0 . 8 7 3}$ & 0.129 & 0.306 \\
PATR3 & 0.049 & -0.094 & $\mathbf{0 . 8 6 0}$ & 0.131 & 0.323 \\
NPSB1 & -0.017 & 0.088 & 0.091 & $\mathbf{0 . 7 2 5}$ & 0.165 \\
NPSB2 & 0.098 & 0.104 & 0.075 & $\mathbf{0 . 7 5 1}$ & 0.160 \\
NPSB3 & -0.006 & 0.080 & 0.147 & $\mathbf{0 . 8 1 8}$ & 0.256 \\
ANGSMO1 & 0.089 & 0.060 & 0.282 & 0.185 & $\mathbf{0 . 8 3 9}$ \\
ANGSMO2 & 0.052 & 0.0283 & 0.3441 & 0.2584 & $\mathbf{0 . 8 9 1}$ \\
\hline
\end{tabular}

Notes: Item loadings are in bold 
Table 3. Construct Reliability (model with interaction effect)

\begin{tabular}{ccccccc}
\hline Construct & CR & Communality & R Square & CA & AVE & Redundancy \\
\hline ANGSMO & 0.857 & 0.749 & 0.000 & 0.668 & 0.749 & 0.000 \\
MNPSEF & 0.844 & 0.729 & 0.000 & 0.629 & 0.729 & 0.000 \\
PATR & 0.894 & 0.738 & 0.135 & 0.822 & 0.738 & 0.098 \\
PATR * MNPSEF & 0.867 & 0.523 & 0.000 & 0.820 & 0.523 & 0.000 \\
NPSB & 0.809 & 0.586 & 0.069 & 0.650 & 0.586 & 0.000 \\
UNSINT & 0.881 & 0.788 & 0.068 & 0.731 & 0.788 & 0.000 \\
\hline
\end{tabular}

Note: AVE - Average variance extracted, CR - Composite reliability, CA - Cronbach alpha

Key: MNPSEF - Mobile number portability-induced self-efficacy, UNSINT - Unswitching Intention, PATR -

Perceived attraction, NPSB - Post-switching behaviour, ANGSMO - Anger-induced switching motive

Convergent validity refers to how indicators together explain a construct and shows the extent to which each measure correlates with other measures of the same latent construct (Hair et al., 2010; Nimako \& Mensah, 2013). Convergent validity is assessed through construct factor (item) loadings, composite reliability (CR) and average variance extracted (AVE) that should have minimum loading of 0.5, 0.80 and 0.50 respectively (Anderson \& Gerbing, 1988; Hair et al., 2010). From Table 2, the factor loadings of items to their respective constructs are stronger than they load on other constructs providing evidence in support of the convergent validity of the derived measures. Also, as shown in Table 3, the CR values, which are in excess of 0.80 are judged acceptable, providing support for convergent validity. The composite reliability values for all constructs range from 0.809 to 0.894 exceeding the acceptable requirement of 0.70 or 0.80 (Bagozzi \& Yi 1988; Hair et al., 2010). Moreover, as shown in Table 3, values for the AVEs are all greater than the recommended minimum of 0.50 (Fornell \& Larcker, 1981), suggesting convergent validity of the constructs.

Discriminant validity refers to the extent to which constructs are distinct from other constructs in the measurement model. At the construct level, discriminant validity is considered adequate when the variance shared between a construct and any other construct in the model is less than the variance which that construct shares with its measures (Fornell and Larcker, 1981). It can be measured through the AVEs and cross loadings. As indicated in Table 4, the AVEs are greater than their respective inter-construct correlation, indicating discriminant validity. Moreover, from the item loading and cross loadings in Table 2, each measurement item for each construct loads higher on their derived construct than on other constructs in the research model in terms of cross loadings. Taken together, the square root of the AVEs and the cross loadings provide strong evidence of discriminate validity (Chin, 2010; Farrell, 2010; Fornell \& Larcker, 1981). Given that construct reliability and validity conditions of the measurement model are acceptable, the results of the structural model can be reliable.

Table 4. Latent Variable Correlations and Discriminant Validity

\begin{tabular}{lrrrrr}
\hline & ANGSMO & MNPSEF & PATR & NPSB & \multicolumn{1}{c}{ UNSINT } \\
\hline ANGSMO & $\mathbf{0 . 8 6 6}$ & & & & \\
MNPSEF & $0.080^{*}$ & $\mathbf{0 . 8 5 4}$ & & & \\
PATR & 0.364 & $0.083^{*}$ & $\mathbf{0 . 8 5 9}$ & & \\
NPSB & 0.260 & $0.028^{*}$ & 0.141 & $\mathbf{0 . 7 6 6}$ & \\
UNSINT & $0.049^{*}$ & $0.066^{*}$ & -0.141 & 0.116 & $\mathbf{0 . 8 8 7}$ \\
\hline
\end{tabular}

Notes: AVEs are in the diagonal; correlations are below the diagonal and are significant at 0.01 or *0.05

Key: MNPSEF - Mobile number portability-induced self-efficacy, UNSINT - Unswitching Intention, PATR Perceived attraction, NPSB - Post-switching behaviour, ANGSMO - Anger-induced switching motive

\subsection{Results of Structural Model}

In PLS-SEM, structural models are assessed through regression weights, t-values, significance (p-values) of the t-statistics, as well as effect sizes of independent variables on the dependent variables. The results in Table 5 show that all the hypotheses were supported by the data, except H5. Specifically, it indicates that UNSINT was significantly influenced by PATR, NPSB, ANGSMO and the interaction effect of MNPSEF, supporting hypotheses H1, H2, H4 and H6. There was no significant direct influence of MNPSEF on UNSINT, disproving H5. Moreover, 
PATR was influenced significantly by ANGSMO, but was not significantly affected by PSB. Furthermore, ANGSMO significantly influenced NPSB.

Table 5. Results of Hypothesis Testing

\begin{tabular}{|c|c|c|c|c|c|c|}
\hline Hypothesis & Hypothesized Relationship & $\begin{array}{l}\text { Regression } \\
\text { Weight } \\
\end{array}$ & $\begin{array}{c}\text { Std. } \\
\text { Error }\end{array}$ & T-statistics & $p$-value & Result \\
\hline 1 & MNPSEF -> UNSINT & 0.071 & 0.040 & 1.758 & $0.040^{*}$ & Supported \\
\hline 2 & PATR -> UNSINT & 0.202 & 0.046 & 4.439 & $* * *$ & Supported \\
\hline 3 & PATR * MNPSEF -> UNSINT & 0.137 & 0.036 & 3.851 & $* * *$ & Supported \\
\hline 4 & NPSB -> UNSINT & 0.120 & 0.041 & 2.906 & $0.002 * *$ & Supported \\
\hline 5 & NPSB -> PATR & 0.050 & 0.047 & 1.060 & 0.145 & Not supported \\
\hline 6 & ANGSMO -> UNSINT & -0.093 & 0.046 & 2.018 & $0.022 *$ & Supported \\
\hline 7 & ANGSMO -> PATR & -0.351 & 0.040 & 8.906 & $* * *$ & Supported \\
\hline 8 & ANGSMO -> NPSB & 0.263 & 0.040 & 6.608 & $* * *$ & Supported \\
\hline
\end{tabular}

Notes: $* * *$ significant at $0.001, * *$ significant at $0.01, *$ significant at 0.05, MNPSEF - Mobile number portability-induced self-efficacy, UNSINT - Unswitching Intention, PATR - Perceived attraction, NPSB - Post-switching behaviour, ANGSMO Anger-induced switching motive

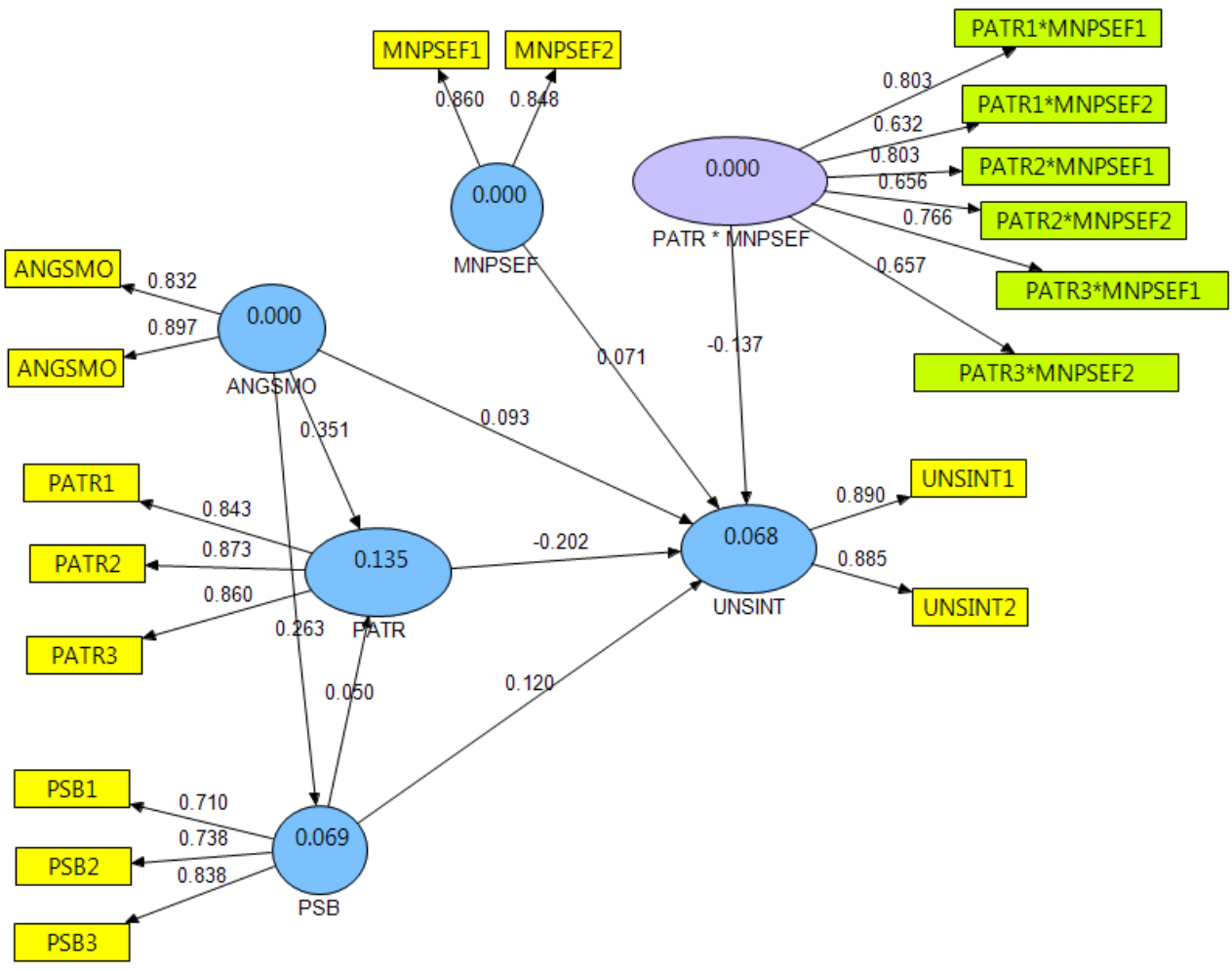

Figure 2. Assessment of Structural Model with Interaction Effect

\subsection{Results of Predictive Power and Effect Sizes}

The R-Square measures the predictive power of the structural model in PLS analysis. According to the guidelines of Cohen (1988), predictive power less than 0.15 indicates small effect size. Therefore, from Table 6, the predictive power of the model as seen in R-square for UNSINT, NPSB and PRT could be described as small, though relevant in the research context. This is probably due to the fact that most of the constructs are newly developed and would require future research to further develop a more complete model. The effect size of each of the dependent variables is presented in Table 6 . Effect size is estimated by:

$$
\frac{R^{2} \text { included }-R^{2} \text { exluded }}{1-R^{2} \text { included }}
$$


Table 6. R-square and Effect Size Analysis

\begin{tabular}{lllll}
\hline Sub-models examined & $\left.\mathbf{( R}^{2}\right)$ Excluded & $\left.\mathbf{( R}^{2}\right)$ Included & f-Squared & Effect size \\
\hline Model without MNSEF & 0.045 & 0.068 & 0.023 & Small \\
Model without ANGSMO & 0.062 & 0.068 & 0.006 & None \\
Model without PATR & 0.019 & 0.068 & 0.053 & Small \\
Model without NPSB & 0.055 & 0.068 & 0.012 & None \\
Model without interaction effect & 0.050 & 0.068 & 0.019 & Small \\
Full model & & $\left.\mathbf{( R}^{2}\right)$ & & \\
UNSINT & & 0.068 & & Small \\
PATR & & 0.135 & & Small \\
NPSB & 0.069 & & Small \\
\hline
\end{tabular}

Note: effective size: 0 - none, 0.02 - small, 0.15 - medium, 0.35 - large (Cohen, 1988).

Cohen (1988) provides the following guidelines for interpreting effect sizes: Less than 0.02 - no effect, Small -0.02 , medium -0.15 , large -0.35 . From Table 6 , while ANGSMO and NPSB have insignificant effect sizes, MNPSEF and PATR have small effect sizes.

\section{Discussion and Implications to Theory and Practice}

The main purpose of this study was to initiate theoretical enquiry into the factors that influence consumer unswitching behaviour, using the mobile telecommunication industry as the research context. Based on the objective analysis of the primary data, the findings indicate that consumer unswitching intentions can be influenced by perceived attraction of competitor's offer (or improvement in previous firm's service delivery), post-switching behaviour and switching motive, except switching efficacy. Switching efficacy, however, was found to moderate the effect of attraction of competitor offer on intention to unswitch. Theoretically, despite the model's low predictive power, the findings provides an initial modelling of factors affecting consumers' intention to unswitch in telecommunication industry. This is an attempt to fill the lack of empirical models for explaining consumer intentions to switch back to former service providers, described as unswitching behaviour.

The study found that perceived attractiveness of competitor's offer could influence consumers to unswitch to their former mobile telecom operators. This means that where consumer's former service provider is able to offer very attractive services, higher service quality and more value or service benefits to customers, switchers can be attracted to make a decision to switch back. Theoretically, it implies that, not only is attractiveness of competitor offer able to influence switching intentions (Bansal et al., 2005), but also it is able to influence unswitching behaviour as confirmed in the present study.

Managerially, the implication is that telecommunication mangers can use improvement in services to persuade defected consumers to switch back and reconnect to them. In this regard, persuasive advertising campaign targeted at influencing consumer intentions to unswitch should highlight attractiveness of benefits that defected customers are likely to gain if they switch back to renew their relationship. Some win-back strategies identified include factors such as identifying potential defectors, communicating with customers, listening to front-line people, treating valuable customers well, being fair, even when you don't have to, using exit barriers carefully, and winning the right customers back (Thompson, 2005). Moreover, the following strategies are recommended for firm attraction of defected customers in mobile telecommunication industry:

- Render apologies and explanation for not being able to satisfy defected consumers.

- Offer no charges for reconnection.

- Increase customer value by providing bundles of services at low prices for consumer who reconnect.

- Provide added value and exciting services while delivering improved services.

- Offer more exciting free internet services for a limited amount of download for customer who reconnect for a specified period.

- Offer special bonus credit to consumers who reconnect periodically.

Moreover, the study reveals that the post-switching behaviour can influence consumers' intentions to unswitch. The explanation is that when consumers engage in negative post-switching behaviour they could become strongly disloyal and opponents to the former service provider. But the underlying cause of such hostile behaviour might be 
due to some anger-motivated switching incidences. This is confirmed by the findings of the present study which showed that anger-induced switching motives significantly affect consumers post-switching behaviour of consumers.

The explanation is that during the switching process, when consumer switching is motivated by anger, it can lead to negative psychological, emotional and behavioural post-switching behaviour. Such consumers with negative post-switching behaviour are more likely have negative mental images of the switching incidence. As a result they may tell personal stories about the switching incidence and make purposeful attempt to prevent or discourage peers, family, friends and other social groups from using the services of the previous service provider (Keaveney, 1995). In this way, it becomes difficult for such switchers to be won back. This implies that there is the need to manage consumer complaints and other critical incidences effectively so that they do not cause consumers to switch in pain and anger.

Furthermore, it was found that switching-efficacy does not necessarily influence intentions to unswitch, rather, it moderates the effect of perceived attraction of competitor's offer on intention to unswitch. Theoretically, this implies that the influence of government regulatory policy (notably MNP) can facilitate not only consumer switching (Buehler and Haucap, 2004; Shin and Kim, 2007) but also unswitching behaviour, as it facilitates both switching to and switching from situations.

To industry regulators, the implication of this finding is that the MNP adoption by consumers appears to be effective in achieving the objective of enhancing consumer switching in an attempt to increase competition for improved service quality in the telecom industry. This confirms the potential effectiveness of MNP implementation in reducing switching costs in the telecommunication industry (Shin and Kim, 2007). Moreover, the findings indicate that mobile network operators could benefit from the MNP policy as it serves as facilitating condition and resource for influencing consumer's decisions to switch back. This should encourage mobile operators to be actively involved in promoting consumer adoption of the MNP policy, especially in developing countries where the policy is relatively new. Thus, the MNP could serve as an effective platform for encouraging defected consumers to switch back when there is attractive offers for reconnection through persuasive adverts.

Finally, the findings imply that telecommunication managers, in an attempt to win back defected customers, should focus on persuasive marketing communication strategy on dealing with negative post-switching behaviour, anger-motivated switching motives, while highlighting the perceived value and improved service conditions being offered to defected customers who renew relationship with the firm.

\section{Limitations and Future Research}

This study assessed the influence of four variables on consumer intention to unswitch to their former service providers in the mobile telecom industry in developing country context. The present study is limited in terms of the predictive power of the research model validated. Despite the model's small predictive power, it offers an initial insight into the possible determinants of a relatively new concept in the switching behaviour literature in the telecommunication service industry.

The implication of this is that switching back behaviour may be influenced by some other variables that have not been captured. Thus, the small predictive power of the model provides avenues for research to examine other critical factors that can affect consumers' unswitching behaviour such as customer service quality of the current service provider, the network quality, perceived value, peer influence, persuasive advertising, apology as well as the moderating role of demographic and religious factors. Future research should extend the research model to incorporate these other variables that can help explain better the concept of consumer unswitching behaviour in the marketing and consumer behaviour research.

\section{Conclusion}

In summary, this paper provides an initial study into the factors that affect consumer intentions to unswitch, a phenomenon which is relatively new in the consumer behaviour literature. Drawing on data from a cross-section of mobile subscribers in six global mobile telecommunication industry in an emerging country context, the papers offers both theoretical and managerial implications. In spite of the small predictive effect of the research model, the results indicated that perceived attraction of competitor's offer, switching motive and post-switching behaviour are significant predictors of consumer intention to unswitch in the telecommunication industry in an emerging economy context. Moreover, it found that MNP adoption by consumers facilitates consumers' switching efficacy, which in 
turn facilitates consumers' decision to switch back. The paper discusses important avenues for future research on consumer intentions to unswitch.

\section{References}

Anderson, J.C., \& Gerbing, D.W. (1988). Structural equation modelling in practice: A review and recommended two step approach. Psychol. Bull, 103(3), 411-423. http://dx.doi.org/10.1037/0033-2909.103.3.411

Bansal, H. S., \& Taylor, S. F. (1999). The service provider switching model (SPSM): A model of consumer switching behavior in the services industry. Journal of Service Research, 21, 200-218. http://dx.doi.org/10.1177/109467059922007

Bansal, H. S., Irving, P. G., \& Taylor, S. F. (2004). A three component model of customer commitment to service provider. Journal of the Academy of Marketing Science, 32(3), 234-250. http://dx.doi.org/10.1177/0092070304263332

Bansal, H. S., Taylor, S. F., \& Y. St. James. (2005). "Migrating" to New Service Providers: Toward a Unifying Framework of Consumers' Switching Behaviors. Journal of the Academy of Marketing Science, 33(1), 96-115. http://dx.doi.org/10.1177/0092070304267928.

Barroso, C., \& Picón, A. (2012). Multi-dimensional analysis of perceived switching costs. Industrial Marketing Management, 41(3), 531-543. http://dx.doi.org/10.1016/j.indmarman.2011.06.020

Belanche, D., Casaló, L. V., \& Guinalíu M. (2013). The Role of Consumer Happiness in Relationship Marketing. Journal of Relationship Marketing, 12(2), 79-94. http://dx.doi.org/10.1080/15332667.2013.794099

Berry, L.L., \& Parasuraman, A. (1991). Marketing Services: Competing Through Quality. Free Press, New York, 1991

Buehler, S., \& Haucap, J. (2004). Mobile Numbering and Number Portability in Ireland. A report to the ODTR, Ovum: London. Journal of Industry, Competition and Trade, 4(3), 223-238. http://dx.doi.org/10.1023/B:JICT.0000047299.13443.5a

DeCarlo, T. E. (2005). The effects of sales message and suspicion of ulterior motives on salesperson evaluation. Journal of Consumer Psychology, 15, 238-249. http://dx.doi.org/10.1207/s15327663jcp1503_9

Farrell, A. M. (2010). Insufficient discriminant validity: A comment on Bove, Pervan, Beatty, and Shiu (2009). Journal of Business Research, 63, 324-327. http://dx.doi.org/10.1016/j.jbusres.2009.05.003

Fornell, C., \& Larcker, D. F. (1981). Evaluating structural equation models with unobservable variables and measurement error. Journal of Marketing Research, 18, 39-50. http://dx.doi.org/10.2307/3151312

Gerrard, P., \& Cunningham, J. B. (2004). Consumer switching behavior in the Asian banking market. Journal of Services Marketing, 18, 215-223. http://dx.doi.org/10.1108/08876040410536512

Göransson, K., \& Frenzel, F. (2009). Switching Behaviour within the Telecommunication Business: A qualitative study of former Telia Sonera customers. Master's thesis, Karlstads universitet, 1- 89.

Gremler, D. D., \& Brown, S.W. (1996). Service loyalty: its nature, importance and implications. In: Edvardsson B, Brown SW, Sohnston R and Scheuing E (eds), QUIS V: Advancing Service Quality: A Global Perspective. New York: ISQA, 171-181.

Hair, J. F., Black, W. C., Babin, B. J., \& Anderson, R. E. (2010). Multivariate Data Analysis. Englewood Cliffs, NJ: Prentice Hall.

Han, S., Lerner, J. S., \& Keltner, D. (2007). Feelings and consumer decision making: The Appraisal Tendency Framework. Journal of Consumer Psychology, 17, 158-168. http://dx.doi.org/10.1016/S1057-7408(07)70023-2

Huang, L.-Y., Hsieh, Y.-J., \& Chang, S.E. (2011). The effect of consumer innovativeness on adoption of location based services. Review of Global Management and Service Science, 1(1), 17-31

Isen, A. M. (2008). Positive affect: Some recent theoretical developments with practical implications. In C. P. Haugtvedt, P.M. Herr, \& F. R. Kardes (Ed.), The Handbook of Consumer Psychology, (pp.273 - 296). New York, NY: Taylor \& Francis Group.

Keaveney, S. M. (1995). Customer switching behavior in service industries: An explorative study. Journal of Marketing, 59(2), 71-82. http://dx.doi.org/10.2307/1252074 
Lin, J. C., \& Lu, H. (2000). Towards an understanding of the behavioral intention to use a Web Site. International Journal of Information Management, 20, 197-208. http://dx.doi.org/10.1016/S0268-4012(00)00005-0

Lin, Y., Chlamtac, I., \& Yu, H. (2003). Mobile number portability. IEEE Network, 17, 8-16. http://dx.doi.org/10.1109/MNET.2003.1233913

Loken, B. (2008). Consumer Psychology: Categorization, Inferences, Affect, and Persuasion. Annual Review of Psychology, 57, 453-485. http://dx.doi.org/10.1146/annurev.psych.57.102904.190136

Nimako, S. G. (2012a). Towards a Comprehensive Definition and Typology of Consumer Switching Behaviour: Unearthing research gaps. Research Journal of Social Science and Management, 2(3), 67-73.

Nimako, S. G. (2012b). Consumer Switching Behaviour: A Theoretical Review and Research agenda. Research Journal of Social Science and Management, 2(3), 74 - 85.

Njite, D., Kim, W.G., \& Kim, L. H. (2008). Theorizing Consumer Switching Behavior: A General Systems Theory Approach. Journal of Quality Assurance In Hospitality \& Tourism, 9(3), 185-217. http://dx.doi.org/10.1080/15280080802412701

Oyeniyi, J. O., \& Abiodun J. A. (2010). Switching cost and customers loyalty in the mobile phone market: the Nigerian experience. Business Intelligence Journal, 3(1), 111-121.

Reinke, T. H. (1998). Local Number portability and local loop competition. Telecommunications policy, 22(1), $73-87$. http://dx.doi.org/10.1016/S0308-5961(97)00058-X

Ringle, C.M., Wende, S., \& Will, S. (2005). SmartPLS 2.0 (M3) Beta. Hamburg. Retrieved from http://www.smartpls.de

Roos, I. (1999b). Switching processes in customer relationships. Journal of Service Research, 2(1), 68-84. http://dx.doi.org/10.1177/109467059921006

Roos, I., Edvardsson, B., \& Gustafsson, A. (2004). Customer Switching Patterns in Competitive and Noncompetitive Service Industries. Journal of Service Research, 6, 256. http://dx.doi.org/10.1177/1094670503255850.

Shin, D. H., \& Kim, W. Y. (2007). Mobile number portability on customer switching behavior: in the case of the Korean mobile market. Info, 9(4), 38-54. http://dx.doi.org/10.1108/14636690710762129

Straub, D., Boudreau, M. C., \& Gefen, D. (2004). Validation Guidelines for IS Positivist Research. Communications of the AIS, 13(24), 380-427.

Thompson, B. (2005).The Loyalty Connection: Secrets to Customer Retention and Increased Profits. CRMguru.com,

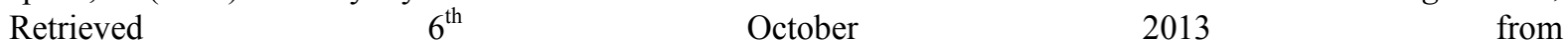
http://ugyfelorientalt.hu/wpcontent/uploads/2013/02/Alojalit\%C3\%A1skapcsolat_RN_LoyaltyCRMGuru.pdf

Tokman, M., Davis, L. M., \& Lemon, K. N. (2007). The WOW factor: Creating value through win-back offers to reacquire lost customers. Journal of Retailing, 83(1), 47-64. http://dx.doi.org/10.1016/j.jretai.2006.10.005

Zeithaml, V.A., Berry L.L., \& Parasuraman A. (1993). The Nature and Determinants of Customer Expectations of Service. Journal of the Academy of Marketing Science, 21(1), 1-12. http://dx.doi.org/10.1177/0092070393211001

Zhang, K.Z.K., Cheung, C.M.K., \& Lee, M.K.O. (2012). Online service switching behavior: The case of blog service providers. Journal of Electronic Commerce Research, 13(3), 184-197. 